\title{
Organizmy pożyteczne w strategiach biologicznego zwalczania - grzyby owadobójcze
}

\begin{abstract}
Wstęp
Coraz większe zużycie środków ochrony roślin i związane z tym skażenie gleby a także obserwowany wzrost odporności owadów na stosowane powszechnie insektycydy zmusza do poszukiwania nowych, alternatywnych i bardziej bezpiecznych dla środowiska, opartych na naturalnej redukcji, metod ograniczania masowych pojawów groźnych szkodników. Jednym z takich sposobów jest zwalczanie biologiczne.

Zwalczanie biologiczne to obecnie cały szereg różnych zabiegów agro - i biotechnicznych w ochronie roślin mających na celu obniżenie populacji zwalczanego szkodnika lub czynnika chorobotwórczego poniżej progu szkodliwości gospodarczej. W ochronie roślin $\mathrm{w}$ zwalczaniu biologicznym wykorzystuje się żywe organizmy tzw. pożyteczne w celu zwalczania organizmów szkodliwych dla roślin uprawnych [1]. Wśród nich szczególną rolę odgrywają grzyby owadobójcze - wyspecjalizowana grupa naturalnych wrogów owadów, zdolna do ich infekcji i wywoływania objawów chorobowych często na masową, epidemiczną skalę, czyli tzw. epizoocje.
\end{abstract}

\section{Strategie biologicznego zwalczania}

Wyróżnia się cztery strategie biologicznego zwalczania: klasyczne zwalczanie biologiczne („clasical biological control”), zachowawcze zwalczanie biologiczne („conservation biological control”), „inoculation biological control” i „inundation biological control" [2]. W opracowaniach w języku polskim dotyczących biologicznego zwalczania nie znalazłam polskich odpowiedników angielskich określeń „inoculation” i ,inundation biological control” dlatego w dalszej części pracy będą one używane w oryginalnym brzmieniu.

Klasyczne zwalczanie biologiczne („clasical biological control”) to zamierzone, świadome wprowadzenie (introdukcja) obcego dla zwalczanej populacji czynnika w celu stałego zadomowienia się go na danym obszarze i wywołania 
długotrwałej ochrony. Najczęściej tym „obcym” czynnikiem są pasożytnicze lub drapieżne zwierzęta (np. pierwotniaki, nicienie, parazytoidy, owady) lub pasożytnicze mikroorganizmy - wirusy, bakterie, grzyby nie występujące na obszarze, na którym zwalczany szkodnik występuje. [3] Introdukowany gatunek aby wywołać długotrwały efekt musi się zaaklimatyzować na danym obszarze w określonych warunkach klimatycznych, rozmnożyć i rozprzestrzenić. Dlatego bardzo ważna jest znajomość biologii zarówno gatunku introdukowanego, jak i zwalczanego, a także możliwość monitorowania jego obecności na danym obszarze [2].

"Inoculation biological control" to również zamierzone uwolnienie (rozproszenie, inokulacja) do środowiska żywych organizmów jako biologicznych czynników ochrony spodziewając się, że zwielokrotnią one swoją liczebność i wywołają efekt w określonym przedziale czasowym. Dobrym przykładem stosowania tej strategii jest użycie parazytoidów czy owadów drapieżnych w celu zwalczania szkodników szklarniowych. Okres ochrony w tym przypadku ogranicza się tylko do czasu wegetacji roślin w szklarni a parazytoidy czy owady drapieżne wprowadza się w niskiej liczebności, stwarzając im jednocześnie warunki do rozmnożenia do poziomu pozwalającego ograniczyć straty spowodowane przez szkodnika do minimum. Strategia ta ma również zastosowanie do użycia pasożytniczych mikroorganizmów, zarówno w szklarniach, jaki i na otwartym terenie, z tym, że uwolnienie mikroorganizmów wymaga najczęściej kilkukrotnego powtórzenia w ciągu sezonu wegetacyjnego [4].

"Inundation biological control" to użycie żywych organizmów (lub produktów ich metabolizmu takich jak toksyny, feromomy, ekstrakty roślinne) w postaci komercyjnie wyprodukowanych środków tzw. biopestycydów. Populacja szkodnika jest niejako zalewana (ang. inundate) biopestycydem w takiej ilości aby uzyskać natychmiastowy efekt (na wzór stosowania chemicznych środków ochrony) [5]. Zachowawcze zwalczanie biologiczne („conservation biological control”) polega na takiej modyfikacji ekosystemów oraz stworzeniu takich warunków w agrocenozach aby podtrzymywać w nich rozwój i obecność wrogów naturalnych. Obecność miedz, zadrzewień śródpolnych, łąk, zbiorników wodnych, ugorów wzbogaca nie tylko bioróżnorodność drapieżców, parazytoidów czy pasożytów ale również bioróżnorodność ich potencjalnych ofiar i gospodarzy [6, 7].

\section{Pasożytnictwo grzybów na owadach}

Sama idea wykorzystania pożytecznych organizmów do walki ze szkodnikami sięga bardzo odległych czasów (już Egipcjanie ponad 4 tys. lat temu ograniczali populacje gryzoni wykorzystując do tego celu koty). Pasożytnictwo na owadach również nie jest zjawiskiem nowym, ale dopiero w XIX wieku zwrócono uwagę na to czy nie wykorzystać go w walce z groźnymi szkodnikami upraw. Pierwsze udokumentowane naukowo przez Agostino Bassi obserwacje chorobo- 
Organizmy pożyteczne w strategiach biologicznego zwalczania - grzyby owadobójcze

twórczego występowania na larwach jedwabnika morwowego grzyba Beauveria bassiana (nazwanego tak później na cześć odkrywcy) miało miejsce w 1835 roku i od tego momentu wzrosło znacznie zainteresowanie biologicznymi metodami zwalczania szkodników i chorób roślin [8].

Patogeny owadów można znaleźć wśród wielu grup systematycznych grzybów. Jednak większość o znaczeniu praktycznym i wykorzystywanych $\mathrm{w}$ różnych strategiach biologicznego zwalczania spotykamy przede wszystkim w dwóch rzędach Hypocreales (gruzłakowców) należących do workowców (Ascomycotina) i Entomophthorales (owadomorkowców) należących do sprzężniaków (Zygomycotina) [9].

Cykl życiowy obu tych grup grzybów jest nieco odmienny, nie mniej jednak warunkiem ich przetrwania i rozprzestrzenienia się w środowisku jest infekowanie i uśmiercanie swoich żywicieli. Aby rozpoczął się proces chorobowy musi najpierw dojść do infekcji gospodarza. Rozwój infekcji grzybowej jest ściśle uzależniony od warunków klimatycznych głównie temperatury i wilgotności, a w przypadku infekcji owadów glebowych właściwości fizyczne i chemiczne gleby. Zarodnik grzyba owadobójczego musi znaleźć się w bezpośrednim kontakcie z ciałem żywiciela. Hypocreales najczęściej występują w przyrodzie w stadium bezpłciowym - konidialnym jako tzw. anamorfy (formy zarodnikowania workowego - płciowego tzw. teleomorfy pojawiają się bardzo rzadko) (rys. 1). Entomophthorales natomiast wytwarzają dwa rodzaje zarodników konidialnych tzw. konidia pierwotne i wtórne. Konidia pierwotne są produkowane na powierzchni owada po jego kolonizacji. Jeżeli po odrzuceniu konidium pierwotne nie trafi na nowego gospodarza kiełkuje w strzępkę, na końcu której tworzy się wtórny zarodnik konidialny. Oba rodzaje zarodników (w odróżnieniu od Hypocreales, które są wiatropylne) odrzucane są w sposób aktywny dzięki wzrastającemu ciśnieniu osmotycznemu zarówno w zarodniku jak i samej komórce zarodnikotwórczej. Owadomorkowce mogą również wytwarzać przetrwalniki pozwalające przetrwać im niekorzystne warunki środowiska bądź okresowy brak żywicieli. W ten sposób synchronizują swój rozwój z rozwojem owadów [10].

Oddziaływanie grzybów z owadami ma charakter obustronny. Z jednej strony grzyby dysponują całym szeregiem przystosowań aby skutecznie atakować swoich żywicieli, z drugiej zaś strony owady również wykształciły szereg różnych przystosowań aby skutecznie bronić się przed infekcjami ze strony entomopatogenów. Kutikula owadów stanowi główną i pierwszą barierę w rozwoju, a potem w penetracji powłok ciała owada przez kiełkujący zarodnik. Zarodniki większości grzybów owadobójczych pokryte są warstwą śluzu złożoną ze związków białka i cukru, co ułatwia im kontakt z powierzchnią kutikuli. W procesie kiełkowania niektóre grzyby owadobójcze wykształcają oprócz strzępki rostkowej również tzw. appresorium, czyli przylgę, za pomocą której zarodnik przytwierdza się do kutikuli owada. Do wnętrza ciała owada (hemocelu) grzyb przenika wytwarzając 
strzępkę infekcyjną. Tam przekształca się w tzw. blastospory, które wypełniają cały hemocel. Sam proces perforacji kutikuli i wnikanie strzępki infekcyjnej do wnętrza ciała owada jest wynikiem enzymatycznej i mechanicznej aktywności kiełkującego zarodnika. Śmierć owada następuje najczęściej w wyniku mechanicznych uszkodzeń narządów wewnętrznych spowodowanych przez rozrastającą się wewnątrz ciała owada grzybnię (mumifikacja) oraz w wyniku produkcji i uwalniania toksyn przez patogena $[9,10]$ (rys. 1). Owady natomiast w obronie przed infekcją wytwarzają na powierzchni oskórka szereg związków chemicznych hamujących kiełkowanie i wzrost zarodników. Stwierdzono, że niektóre kwasy tłuszczowe na powierzchni oskórka larw Heliothis zea hamują kiełkowanie zarodników Beauveria bassiana i Isaria fumosorosea (dawniej Paecilomyces fumosoroseus. Również grzyby i bakterie saprofityczne, zazwyczaj nie chorobotwórcze dla samych owadów, a znajdujące się na powierzchni ich oskórka mają istotny wpływ na kiełkowanie zarodników grzybów owadobójczych $[9,11]$.

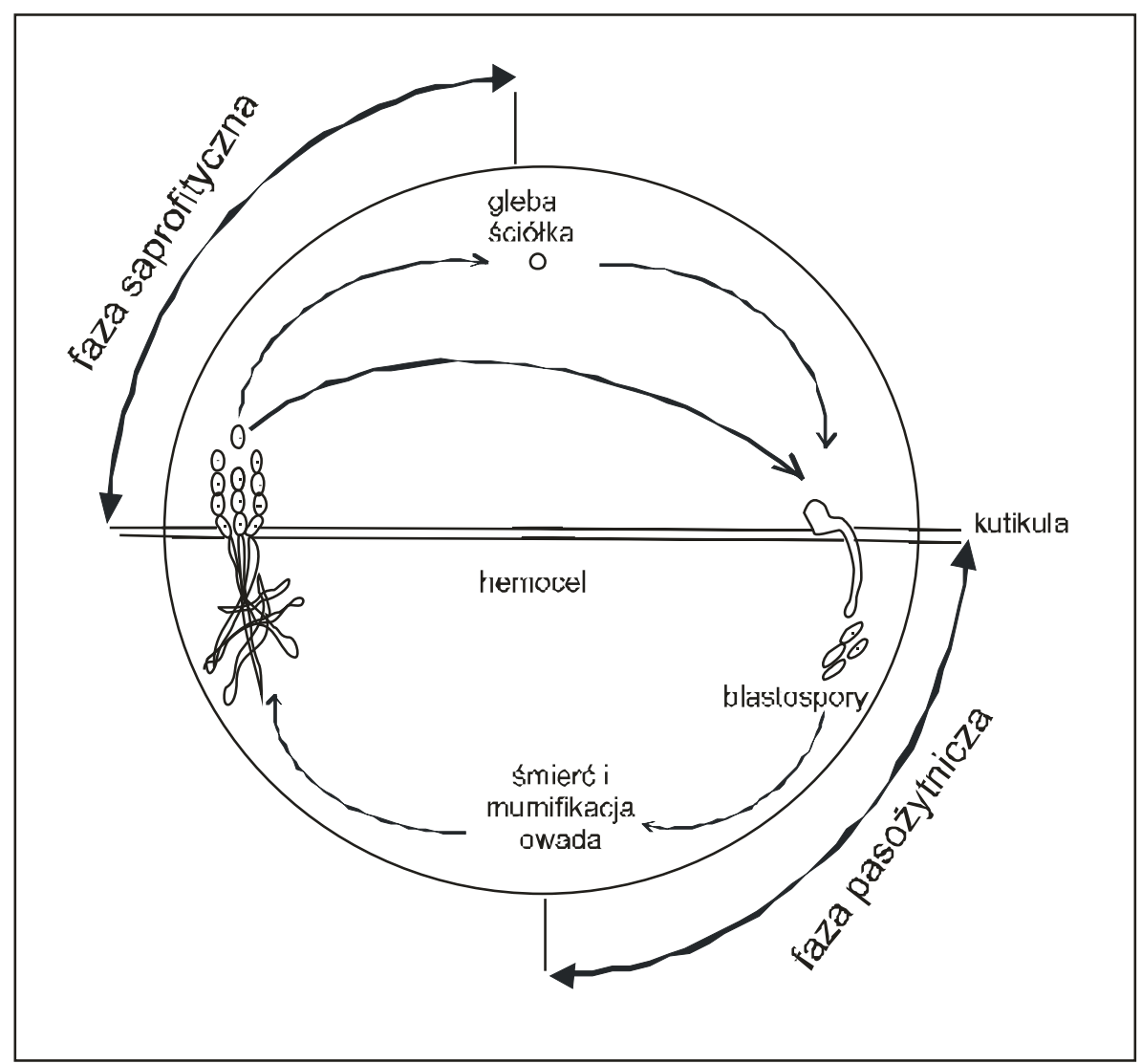

Rysunek 1. Cykl życiowy grzybów owadobójczych z rzędu Hypocreales 
Organizmy pożyteczne w strategiach biologicznego zwalczania - grzyby owadobójcze

\section{Od teorii do praktyki}

Jako pierwszy próbę wyhodowania na sztucznej pożywce zarodników grzyba Metarhizium anisopliae podjął Miecznikow w 1878 roku. Zarodnikami tego grzyba próbował zwalczać larwy nałaka czarnego (Anisoplia austriaca) i szarka komośnika (Bothynoderes punctiventris). Natomiast pierwszy znany biopreparat zawierający zarodniki grzyba M. anisopliae wyprodukował na "szeroką" skalę Krassilszczik. W ciągu czterech miesięcy używając jako podłoża wytłoków jęczmiennych z produkcji piwa wyprodukował około $50 \mathrm{~kg}$ biopreparatu, który po zmieszaniu z piaskiem zastosował do zwalczania komośnika buraczanego (Cleonus punctiventris) w okolicach Kijowa osiągając śmiertelność szkodnika na poziomie $55-80 \%$. Sukcesy te przyczyniły się, zwłaszcza w latach pięćdziesiątych XX w., do znacznego wzrostu zainteresowania biologicznymi metodami walki ze szkodnikami przy użyciu grzybów owadobójczych i prób produkcji na ich bazie biopreparatów $[8,12,13]$.

Strategią, w której najszersze zastosowanie znalazły grzyby owadobójcze jest „inundation biological control” czyli właśnie w postaci komercyjnie produkowanych biopreparatów. Wykorzystanie danego mikroorganizmu w praktyce jest uwarunkowane przede wszystkim możliwością jego masowej i taniej hodowli na sztucznych podłożach. Ponadto muszą charakteryzować się wysoką wirulencją i specjalizacją pasożytniczą aby skutecznie redukować populację zwalczanego szkodnika, być bezpieczne dla organizmów pożytecznych, zwierząt stałocieplnych i ludzi, oraz charakteryzować się wysoką przeżywalnością w warunkach polowych a także podczas długotrwałego przechowywania $[14,15]$. Wirulencja (czyli zjadliwość) to zdolność do wniknięcia, namnożenia się oraz uszkodzenia tkanek zainfekowanego organizmu przez patogena. Poszczególne szczepy grzybów owadobójczych należące nawet do jednego gatunku mogą różnić się wirulencją. Miarą wirulencji jest tzw. śmiertelna dawka letalna $\left(\mathrm{LD}_{50}\right)$ definiowana, jako liczba komórek danego drobnoustroju zdolnych do zabicia 50\% wystawionych na ich działanie osobników testowych lub średni czas zamierania $\left(\mathrm{LT}_{50}\right)$ czyli czas, w którym badany czynnik (szczep drobnoustroju) uśmierca $50 \%$ osobników testowych. Przy ocenie ryzyka stosowania danego mikroorganizmu w biologicznym zwalczaniu bardzo istotną cechą jest ich specjalizacja pasożytnicza. Niestety większość biopreparatów produkowanych jest na bazie grzybów z rzędu Hypocreales, wśród których zdecydowana większość należy do tzw. gatunków polifagicznych czyli o szerokim spektrum potencjalnych gospodarzy (Tabela 1). Natomiast owadomorkowce wśród których wiele gatunków jest monofagicznych i w związku z tym bardziej wyspecjalizowanych nie znajduje jednak zainteresowania wśród potencjalnych producentów biopreparatów z uwagi na trudności w ich hodowli na sztucznych podłożach i namnażaniu materiału infekcyjnego na masową skalę [16]. 
Przeżywalność biopreparatów w warunkach polowych i podczas przechowywania jest natomiast uzależniona w głównej mierze od odpowiedniej ich formulacji. Najczęściej stosowane formulacje dla biologicznych środków ochrony roślin to formulacje stałe w postaci proszku (WP Wettable Powder) lub granul (GR Granule) do sporządzania zawiesiny wodnej, bądź jako zawiesina olejowa (formulacja płynna) (OD Oil Dispersion). Odpowiednia formulacja ułatwia ponadto aplikację biopreparatu i chroni komponent żywy biopreparatu przed wpływem czynników abiotycznych takich jak promieniowanie UV czy też zabezpieczają po oprysku przed zmyciem przez wodę z powierzchni liści [15, 17].

\section{Rejestracja biologicznych środków ochrony roślin}

W Polsce biologiczne środki ochrony roślin zawierające mikroorganizmy aby mogły być stosowane powszechnie muszą być zarejestrowane zgodnie z zasadami podanymi w ustawie z 18 grudnia 2003 o ochronie roślin (Dz.U. z 2004 r. nr11, poz. 94) i aby mogły być stosowane w innych krajach muszą być zarejestrowane również na poziomie Unii Europejskiej (Dyrektywa UE 91/414) [18]. Obecnie na terenie Polski i krajów członkowskich UE dopuszczony jest tylko jeden preparat o handlowej nazwie Preferal na bazie owadobójczego grzyba Isaria fumosorosea (dawna nazwa Paecilomyces fumosoroseus) [19], chociaż w kolejce na ocenę i rejestrację czekają biopreparaty na bazie zarodników B. bassiana, B. brongniartii, M. anisopliae czy Lecanicillium sp. (Tabela 1) [20]. Tak niewielka liczba zarejestrowanych biopreparatów zawierających w swoim składzie mikroorganizmy wynika z narzuconych przez UE bardzo skomplikowanych, kosztownych (koszty rzędu kilku mln euro) i długotrwałych procedur (6-8 lat). W procesie rejestracyjnym główny nacisk w ocenie biopreparatu kładzie się na testy ekotoksykologiczne, czyli jego wpływ na gatunki niebędące celem bezpośredniego zwalczania, a więc przede wszystkim na owady pożyteczne (zapylacze, owady drapieżne, parazytoidy), ale również na organizmy stałocieplne w tym człowieka oraz inne elementy środowiska $[14,21]$. Powstała w związku z tym również potrzeba standaryzacji metod oceny ryzyka stosowania biopestycydów. Odpowiedzią na to były dwa duże projekty finansowane przez Unię Europejską ERBIC („Evaluating Environmental Risks of Biological Control”) i REBECA („Regulation of Biological Control Agents"). Celem pierwszego z nich była ocena wpływu różnych biologicznych środków ochrony roślin na agrocenozy i środowisko oraz ich wpływ na bioróżnorodność, opracowanie szybkich i standardowych metod oceniających ryzyko importu i stosowania biologicznych środków ochrony oraz opracowanie wytycznych zgodnie z którymi stosowanie biopestycydów byłoby bezpieczne [14]. Celem projekt REBECA oprócz oceny ryzyka produkcji i stosowania biologicznych środków ochrony było przede wszystkim opracowanie narzędzi prawnych regulujących i ułatwiających proces rejestracji biopestycydów 
na terenie krajów członkowskich UE (ze szczegółami można zapoznać się na www.rebeca-net.de).

Tabela 1. Lista biopreparatów na bazie grzybów owadobójczych w trakcie rejestracji oraz zakres zakazanych gospodarzy

\begin{tabular}{|c|c|c|}
\hline $\begin{array}{l}\text { Gatunek grzyba } \\
\text { owadobójczego }\end{array}$ & $\begin{array}{l}\text { Nazwa handlowa } \\
\text { biopreparatu }\end{array}$ & Zwalczany organizm (rząd i rodzina) \\
\hline \multirow{8}{*}{$\begin{array}{l}\text { Beauveria } \\
\text { bassiana }\end{array}$} & Trichobass-P & $\begin{array}{l}\text { Coleoptera (Curculionidae, Scarabaeidae), Hemiptera } \\
\text { (Aleyrodidae) }\end{array}$ \\
\hline & Trichobass-L & $\begin{array}{l}\text { jak Trichobass-P + Lepidoptera (Castniidae, Pieridae), } \\
\text { Thysanoptera (Thripidae) }\end{array}$ \\
\hline & BotaniGard ES & $\begin{array}{l}\text { Coleoptera (Curculionidae, Scarabaeidae), Hemiptera } \\
\text { (Miridae, Aleyrodidae, Aphididae, Pseudococcidae, } \\
\text { Psyllidae), Thysanoptera (Thripidae) }\end{array}$ \\
\hline & BotaniGard $22 \mathrm{WP}$ & $\begin{array}{l}\text { jak BotaniGard ES + Hemiptera (Cicadellidae, } \\
\text { Fulgoridae) }\end{array}$ \\
\hline & Mycotrol-ES & $\begin{array}{l}\text { jak BotaniGard ES + Coleoptera (Chrysomelidae), } \\
\text { Hemiptera ( Cicadellidae, Fulgoridae), Orthoptera } \\
\text { (Acrididae, Tettgoniidae) }\end{array}$ \\
\hline & Mycotrol-O & $\begin{array}{l}\text { jak BotaniGard ES + Coleoptera (Chrysomelidae), } \\
\text { Hemiptera (Cicadellidae, Fulgoridae), Lepidoptera } \\
\text { (Crambidae, Noctuidae, Pieridae, Plutellidae) }\end{array}$ \\
\hline & Mycotrol-WP & $\begin{array}{l}\text { jak BotaniGard ES + Coleoptera (Chrysomelidae), } \\
\text { Lepidoptera (Crambidae), Orthoptera (Acrididae, } \\
\text { Tettgoniidae) }\end{array}$ \\
\hline & Naturalis L & $\begin{array}{l}\text { jak BotaniGard ES + Coleoptera (Chrysomelidae), } \\
\text { Diptera (Ephydridae, Mycetophilidae, Sciaridae, } \\
\text { Tipulidae), Hemiptera (Lygaeidae, Cercopidae, } \\
\text { Cicadellidae), Lepidoptera (Crambidae, Gelechiidae, } \\
\text { Geometridae, Noctuidae, Tortricidae), Orthoptera } \\
\text { (Acrididae, Gryllotalpidae), Thysanoptera (Thripidae) }\end{array}$ \\
\hline B. brongniartii & \begin{tabular}{|l|} 
Melocont- \\
Pilzgerste \\
\end{tabular} & Coleoptera (Scarabaeidae) \\
\hline $\begin{array}{l}\text { Isaria } \\
\text { fumosorosea }\end{array}$ & Preferal & Hemiptera (Aleyrodidae) \\
\hline $\begin{array}{l}\text { Lecanicillium } \\
\text { longisporum }\end{array}$ & Vertalec & Hemiptera (Aphididae) \\
\hline L. muscarium & Mycotal & Hemiptera (Aleyrodidae), Thysanoptera (Thripidae) \\
\hline $\begin{array}{l}\text { Metarhizium } \\
\text { anisopliae }\end{array}$ & Granmet-P & Coleoptera (Curculionidae, Scarabaeidae, Nitidulidae) \\
\hline
\end{tabular}

Źródło: Faria i in. 2007 [20]. 


\section{Zakończenie}

Zapewne nie wyeliminujemy całkowicie stosowania chemicznych środków ochrony roślin. Zgodnie ze współczesnym podejściem do problemu ograniczania szkód w uprawach biologiczne zwalczanie powinno być stosowane nie zamiast ale obok metod chemicznych ( $\mathrm{w}$ tzw. integrowanych metodach ang. integrated pest management). Metody biologicznego zwalczania nie mogą być wprowadzane jako środek interwencyjny ponieważ przy klęskowych pojawach owadów (gradacjach), wtedy gdy uprawy można uratować tylko natychmiastowym zniszczeniem szkodnika niezbędne będzie niestety zastosowanie walki chemicznej. Lekkomyślnością jest stosowanie chemicznych preparatów wtedy gdy liczebność szkodnika jest niewielka lub dopiero zaczyna narastać. Wtedy właśnie jest miejsce dla wolniej, ale za to w dłuższym okresie czasu działających biopreparatów.

\section{Bibliografia}

[1] Nordlund D.A. 1996. Biological control, integrated pest management and conceptual models. Biocontrol News and Information 17: 35N-44N.

[2] Eilenberg J., Hajek A., Lomer C. 2001. Suggestion for unifying the terminology in biological control. BioControl 46: 387-400.

[3] Hajek A.E., Delalibera I. Jr. 2010. Fungal pathogens as classical biological control agents against arthropods. BioControl 55: 147-158.

[4] van Lenteren J.C. 2000. Success in biological control of arthropods by augmentation of natural enemies. W: G. Gurr and S. Wratten (eds.), Biological Control, Measures of Success. Kluwer Academic Publishers, Dordrecht/Boston/London. pp. 77-103.

[5] Bateman R.P., Luke B. 2000. Interpreting mycoinsecticide field performance; an uneasy relationship with chemical pesticide paradigm. British Crop Protection Conference, Proceedings 74: 89-100.

[6] Bałazy S. 2004. Znaczenie obszarów chronionych dla zachowania zasobów grzybów entomopatogenicznych. Kosmos 53(1): 5-16.

[7] Landis D.A., Wratten S.D., Gurr G.M. 2000. Habitat management to conserve natural enemies of arthropod pests in agriculture. Annual Review of Entomology 45: 175-201.

[8] Sandner H. 1971. Biologiczne metody ochrony roślin. PWRiL, Warszawa.

[9] Bałazy S. 2000. Zróżnicowanie grup funkcyjnych grzybów owadobójczych. Biotechnologia 3(50): 11-32.

[10] Hajek, A.E. 1997 Ecology of terrestrial fungal entomopathogens. Advances in Microbial Ecology 15: 193-249.

[10] Hajek A.E., St. Leger R.J. 1994. Interactions between fungal pathogens and insect host. Annual Review of Entomology 39: 293-322.

[11] Smith R.J., Grula E.A. 1982. Toxic components on the larval surface of the corn earworm (Heliothis zea) and their effects on germination of Beauveria bassiana. Journal of Invertebrate Pathology 39: 15-22.

[12] Lord J.C. 2005. From Metchnikoff to Monsanto and beyond: the path of microbial control. Journal of Invertebrate Pathology 89: 19-29.

[13] Bajan C. 2000. Od badań szczegółowych do preparatu grzybowego. Biotechnologia 3(50): 58-64.

[14] van Lenteren J.C., Babendreier D., Bigler F., Burgio G., Hokkanen H.M.T., Kuske S., Loomans A.J.M., Menzler-Hokkanen I., van Rijn P.C.J., Thomas M.B., Tommasini M.G., Zeng Q.-Q. 
2003. Environmental risk assessment of exotic natural enemies used in inundative biological control. BioControl 48: 3-38.

[15] Jackson M.A., Dunlop C.A., Jaronski S.T. 2010. Ecological consideration in producing and formulating fungal entomopathogens for use in insect biocontrol. BioControl 55: 129-145.

[16] Pell J.K., Eilenberg J., Hajek A.E., Steinkraus D.C. 2001. Biology, ecology and pest management potential of Entomophthorales. W: T.M. Butt, C.W. Jackson and N. Magan (eds.), Fungi as biocontrol agents: progress, problems and potential. CABI International, Oxon, pp. 71-153.

[17] Crop Life International 2002. Catalogue of pesticide formulation types and international coding system. Technical Monograph $\mathrm{n}^{\circ} 2,5^{\text {th }}$ eds. (dostępne również na www. croplife.org/ monographs.aspx)

[18] Dyrektywa Rady UE 91/414/EWG z 15 lipca 1991 roku o wprowadzeniu na rynek środków ochrony roślin. Dziennik Urzędowy Wspólnoty Europejskiej L230: 1-32.

[19] Tomalak M. 2007. Rejestracja biologicznych środków ochrony roślin w Europie - Nowe perspektywy. Progress in Plant Protection/Postępy w Ochronie Roślin 47(4): 233-240.

[20] Faria M.R., Wraight S.P. 2007. Mycoinsecticides and mycoacaricides: a comprehensive list with worldwide coverage and international classification of formulation types. Biological Control 43: 237-256.

[21] Bigler F., Bale J.S., Cock M.J.W., Dreyer H., Greatrex R., Kuhlmann U., Loomans A.J.M., van Lenteren J.C. 2005. Guidelines on information requirements for import and release of invertebrate biological control agents in European countries. Biocontrol News and Information 26(4): $115 \mathrm{~N}-123 \mathrm{~N}$

\title{
Beneficial organisms in biological control strategies - entomopathogenic fungi
}

\author{
SUMMARY
}

Fungal entomopathogens are widespread in nature and contribute to the natural regulation of insects. They can be exploited for pest management as biological control agents of pests in attempts to improve the sustainability of crop protection.

Four types of biological control are recognized: classical, inoculation, inundation and conservation biological control. Classical biological control is the intentional introduction and permanent establishment of an exotic biological agent for long-term pest management. Inoculation biological control is the intentional release of a living organism as a biological control agent with the expectation that it will multiply and control the pest for an extended period, but not permanently. Inundation biological control is the release of large numbers of mass-produced biological control agents to reduce a pest population without necessarily achieving continuing impact or establishment. Conservation biological control is a such modification of the environment or existing practices to protect and enhance specific natural enemies or other organisms to reduce the effect of pests.

The traditional and the most popular approach in biological control with entomopathogenic fungi has been to apply the fungal material to the cropping system 
(as biopesticide), using an inundation biological control strategy. The term biopesticide is used for microbial biological pest control agents that are applied in a similar manner to chemical pesticides. The use of biopesticides can substitute for some (but not all) chemicals and provide environmentally safe and sustainable control of pests but EU legislation and prohibitive registration costs are discouraging the development and commercialisation of many promising new products.

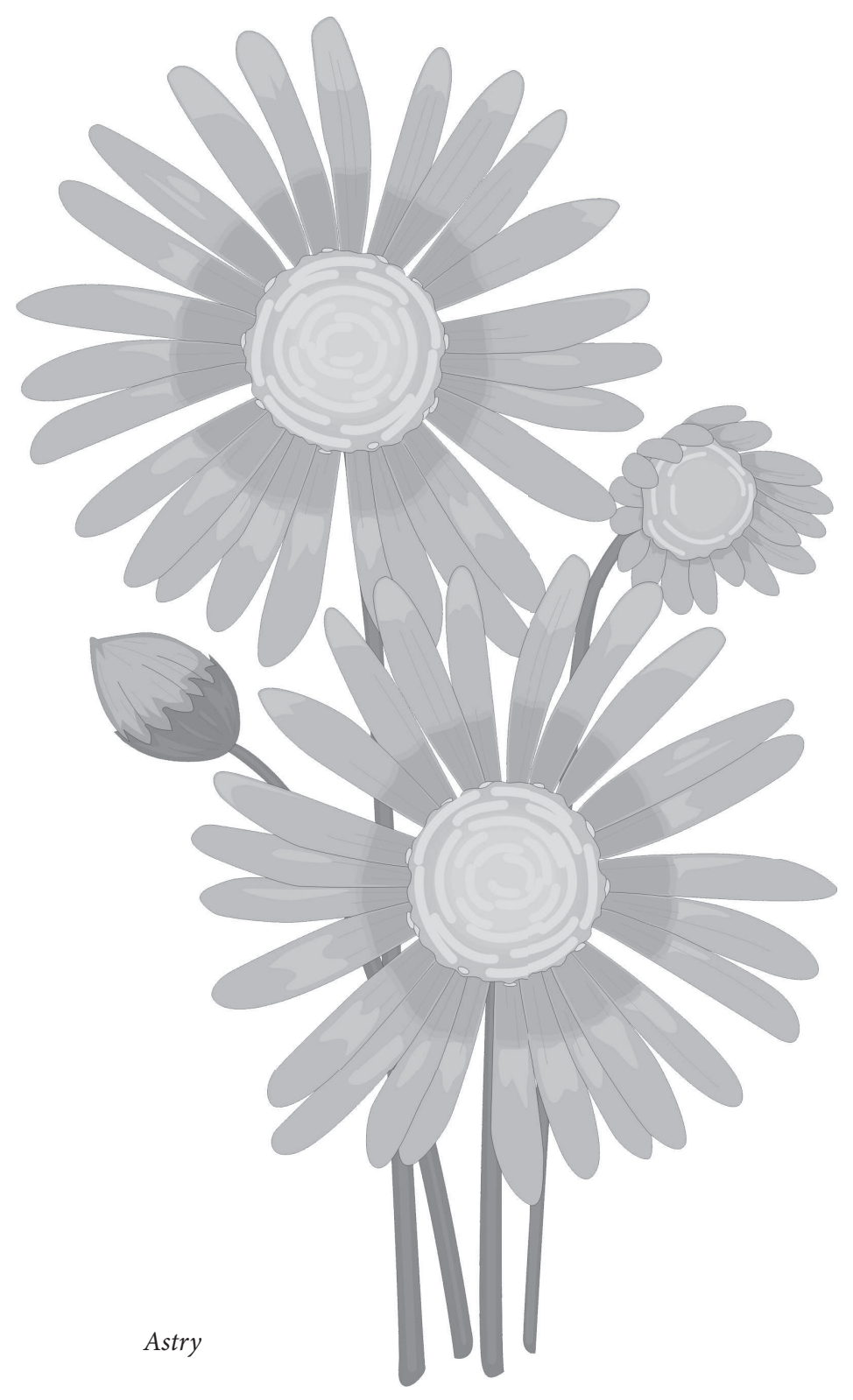

